\section{HYBRID REPAIR IS AN EFFECTIVE STRATEGY FOR REPAIR OF KOMMERELL DIVERTICULUM IN THE MODERN ERA}

To the Editor:

The article by Tsukui and colleagues, ${ }^{1}$ which is based on their experience of 4 cases, makes a provocative argument in favor of total arch replacement as a reasonable option for the surgical treatment of Kommerell diverticulum. Although we concur with Tsukui and colleagues ${ }^{1}$ that there is no consensus regarding the optimal surgical strategy for repair of Kommerell diverticulum, we believe that the type of intervention can be tailored to the anatomy, comorbidities, and surgical expertise. There is an increasing role for hybrid repair in treating this pathologic entity. In our experience with 10 patients with Kommerell diverticula treated with a hybrid approach, we have demonstrated safety and effectiveness with a less invasive alternative for treating this pathology. Our techniques use stent grafts in combination with open surgery aided by the use of modern imaging. $^{2}$

We were surprised to see that 2 of the patients in the series of Tsukui and colleagues ${ }^{1}$ with maximum aortic diameters of only 20 and $25 \mathrm{~mm}$ also had a presentation of dysphagia. It has been our practice to observe smaller Kommerell diverticula such as these, because there is often another cause for the dysphagia.

\footnotetext{
The Editor welcomes submissions for possible publication in the Letters to the Editor section that consist of commentary on an article published in the Journal or other relevant issues. Authors should: - Include no more than 500 words of text, three authors, and five references. - Type with double-spacing. - See http://jtcs.ctsnetjournals.org/misc/ifora.shtml for detailed submission instructions. - Submit the letter electronically via jtcvs.editorialmanager.com. Letters commenting on an article published in the JTCVS will be considered if they are received within 6 weeks of the time the article was published. Authors of the article being commented on will be given an opportunity of offer a timely response ( 2 weeks) to the letter. Authors of letters will be notified that the letter has been received. Unpublished letters cannot be returned.
}

Prophylactic repair to address the risk of rupture or dissection has been recommended for aneurysmal sizes larger than $3 \mathrm{~cm}$; however, the morphology of Kommerell diverticula is complex and often asymmetric. ${ }^{3}$ Our method of measuring the Kommerell diverticulum consists of taking measurements in 2 dimensions, orthogonal to the course of the aorta. The first measurement is taken at a level near the origin of the aberrant subclavian artery from the arch, and in this plane a diameter of at least 3 $\mathrm{cm}$ is considered an indication to operate. The second is taken across the cross-sectional diameter from the opposite aortic wall to the tip of the Kommerell diverticulum. When this measurement exceeds $5 \mathrm{~cm}$, we recommend prophylactic repair. ${ }^{2}$

We also wondered why the patients all had unusually long stays in the hospital, including a stay of 291 days. ${ }^{1}$ In our experience, with the use of a hybrid technique to avoid the additional thoracotomy, the mean stay was $8.7 \pm 4$ days.

We agree with Tsukui and colleagues ${ }^{1}$ about the need for definitive treatment to include division of the ligamentum. With our method, however, this can be achieved with 1 incision instead of 2 . $^{2}$

We commend Tsukui and colleagues ${ }^{1}$ for their article, and we suggest that options for repair of Kommerell diverticulum may safely include hybrid techniques.

Suresh Keshavamurthy, MD Jahanzaib Idrees, MD Eric E. Roselli, $M D$ Department of Thoracic and Cardiovascular Surgery Cleveland Clinic Cleveland, Ohio

\section{References}

1. Tsukui H, Aomi S, Yamazaki K. Surgical strategy for Kommerell's diverticulum: total arch replacement. J Thorac Cardiovasc Surg. 2013 Dec 20.

2. Idrees J, Keshavamurthy S, Subramanian S, Clair DG, Svensson LG, Roselli EE. Hybrid repair of Kommerell diverticulum. 2014;147:973-6.
3. Kouchoukos NT, Masetti P. Aberrant subclavian artery and Kommerell aneurysm: surgical treatment with a standard approach. J Thorac Cardiovasc Surg. 2007;133:888-92.

http://dx.doi.org/10.1016/ j.jtcvs.2014.02.034

\section{Reply to the Editor:}

We thank Keshavamurthy and colleagues for their letter regarding our article. We also read with interest their group's article, "Hybrid Repair of Kommerell Diverticulum," recently published in The Journal of Thoracic and Cardiovascular Surgery. ${ }^{1}$ They used stent-grafts in combination with open surgery aided by imaging.

Our series included 2 patients with a relatively small aortic diameter. $\mathrm{Pa}$ tient 4, a 38-year-old man, had Kommerell diverticulum with a diameter of only $25 \mathrm{~mm}$; however, he had dysphagia, and preoperative esophagography showed esophageal stenosis (Figure 1, A). Postoperative esophagography showed improvement of the esophageal stenosis consequent to complete release of the vascular ring (Figure 1, B). We believe that even if the diameter of a Kommerell diverticulum is small, 2 of the mechanisms hypothesized by Backer, "sling-like effect" and "bowstring effect," create tracheal and esophageal compression. For prophylactic repair to prevent rupture or dissection, the size of the Kommerell diverticulum should be considered as an indication, and the measurement methods by the Cleveland clinic group may be appropriate. If the patient has dysphagia, however, there is an indication to operate even in cases with small diameter.

One of our patients had a long period of hospitalization. He was 72 years old when he had surgery and had a complex medical history, including myocardial infarction, renal insufficiency, and colon cancer. In addition to postoperative respiratory failure, he had rhabdomyolysis in response to medication for dyslipidemia. The combination of these conditions resulted in prolonged hospitalization. This kind of 